\title{
Política pública dos telecentros e prevenção da violência
}

DR. GILSON LIMA* VIVIAN FURTADO**

\section{Resumo}

Este artigo é a sistematização de parte de uma pesquisa que foi realizada no núcleo "Violência e Cidadania do Programa de Pós-Graduação", da Universidade Federal do Rio Grande do Sul, no período de 2006 a 2008. Buscaremos, a partir de dados documentais e de entrevistas coletadas, apresentar uma concepção e uma análise do caso da política pública de inclusão digital através dos telecentros na capital do Rio Grande do Sul (Porto Alegre). Discutiremos nesse artigo a concepção de inclusão digital que encontramos presente tanto junto aos primeiros gestores que conceberam a Política Pública Municipal dos Telecentros em Porto Alegre (2004), como aos atuais gestores (2007) que dão continuidade à execução dessa política pública. Realizaremos uma análise dessas concepções, ressaltando suas virtudes e seus limites diante da abordagem teórica da modernidade reflexiva por nós adotada. Nossas palavras finais têm em vista defender e indicar uma maior e melhor integração entre a política de inclusão digital dos telecentros e a prevenção de violência para jovens de baixa renda, sobretudo da população de risco, que se situa entre 15 e 18 anos. Defendemos também a integração da política de inclusão digital para essa população a ser ampliada com uma política de renda e bolsas de inclusão escolar de longo prazo.

Palavras-chave: Inclusão digital. Prevenção da violência. Análise de políticas públicas.

\footnotetext{
* Doutor em Sociologia pela Universidade Federal do Rio Grande do Sul - UFRGS. Professor e pesquisador do Mestrado de Reabilitação e Inclusão da Rede Metodista de Educação do Sul (IPA), em Porto Alegre - RS. Pesquisador do CEDCIS - Centro de Estudos e Difusão de Conhecimento, inovação e sustentabilidade e pesquisador do LaDCIS - Laboratório de Difusão de Ciência, Tecnologia e Inovação Social. Colaborador do Núcleo de Violência e Cidadania do Programa de PósGraduação em Sociologia pela Universidade Federal do Rio Grande do Sul - UFRGS. E-mail: gilima@gmail.com

** Estudante do curso de Ciências Sociais da Universidade Federal do Rio Grande do Sul - UFRGS e bolsista de Iniciação Científica. E-mail: vivian_furtado@ig.com.br
} 


\section{Introdução: localizando a pesquisa}

1.1 Da Cidade de Porto Alegre

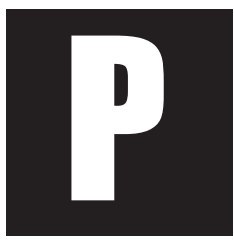

orto Alegre é uma cidade balneária. Situa-se diante de um grande estuário chamado Guaíba, onde deságuam cinco rios, que se juntam antes de entrarem em uma lagoa denominada Lagoa dos Patos, uma das mais extensas do País.

A partir da década de 1990, a cidade recebeu reconhecimento nacional pela sua qualidade de vida conforme o IDH-M (Índice de Desenvolvimento Humano Municipal). A cidade ocupa atualmente a 11aㅡ posição no ranking das cidades brasileiras em qualidade de vida, sendo a primeira entre as cidades com mais de 1 milhão de habitantes. A expectativa de vida na cidade está em 72,6 anos. O índice de alfabetização é de 89,5\%.

Dos quinze municípios do País com mais de um milhão de habitantes, Porto Alegre é a 10ª cidade do País em população.

Porto Alegre, em 2004, ocupou o lugar de 19a cidade no ranking do País por mortes por 100.000 habitantes, 41 mil homicídios; 3,63\% de suicídios por 100.000 habitantes e 13,30\% de mortes no trânsito por 100,000 habitantes.

\section{$1.2 \mathrm{O}$ que são os Telecentros?}

Trata-se de um programa de inclusão digital iniciado em 2001, na gestão do Partido dos Trabalhadores (PT). É um espaço de acesso público e gratuito, com computadores conectados à Internet. São espaços instalados pela Prefeitura Municipal na cidade de Porto Alegre. Os Telecentros são especificamente voltados para possibilitar gratuitamente acesso à rede digital, e, particularmente, à Internet/Web para jovens de baixa renda.

Cada unidade de Telecentro tem, em média, doze microcomputadores, scanner e impressora. Os equipamentos são fornecidos pela Prefeitura Municipal de Porto Alegre e, em alguns casos, são originários de doações de empresas públicas e privadas. 
Atualmente os Telecentros constituem-se em uma política pública da Prefeitura Municipal de Porto Alegre, política cuja execução e coordenação é de responsabilidade da Secretaria Municipal de Direitos Humanos e Segurança Urbana, em parceria com a Procempa (Empresa de Processamento de Dados), também da Prefeitura Municipal de Porto Alegre.

1.3 A que jovens estamos nos referindo na pesquisa e por quê?

Quando falamos em jovens na pesquisa, estamos referindo-nos a jovens de baixa renda, principalmente entre quinze e dezoito anos.

Por que essa faixa de idade? Porque, segundo pesquisas amplamente conhecidas no Brasil, é nesta faixa de idade que mais morrem jovens envolvidos em violência nas grandes cidades.

Os indicadores das mortes violentas destes jovens mostram que essas mortes, majoritariamente, têm relação com questões direta ou indiretamente envolvidas com o tráfico de drogas. Também é nessa faixa de idade, principalmente, dos 15 aos 18 anos, que se verifica a base inicial do recrutamento do comércio de varejo pela economia "clandestina" do narcotráfico".

O ciclo desse recrutamento perverso da juventude já foi identificado por inúmeras pesquisas sociológicas e antropológicas realizadas no País. O envolvimento com as drogas inicia-se com o vício, passa pelo endividamento dos jovens, por não conseguirem renda que assegure o acesso às drogas, e termina com o recrutamento desses jovens pelo comércio do tráfico como meio de pagamento de suas dívidas. Assim, os jovens recrutados pelo tráfico, pressionados por traficantes e policiais, passam a integrar, em fileiras crescentes, a rede de delitos criminosos no País, que se expande em escala geométrica, sobretudo após a chegada da cocaína e do tráfico industrial em rede mundializada (CASTELLS, 1999a).

1 A análise da violência contra a criança e o adolescente, segundo o ciclo de vida no Brasil, lançada pelo UNICEF e o observatório de favelas do Rio de Janeiro em agosto último, demonstra que na faixaetária entre 0 a 18 anos os maiores alvos de homicídios são meninos de 15 a 18 anos (nesta pesquisa as informações vêm da síntese dos indicadores sociais 2003, IBGE). Ver também ZALUAR, 1999. 
Com a industrialização e a agregação em complexas redes transnacionais da economia "clandestina" do narcotráfico, o padrão do crime e da violência nas cidades brasileiras se alterara significativamente, como demonstram diversos estudos e pesquisas realizadas sobre o tema.

Assim, a vulnerabilidade dos adolescentes de baixa renda entre 15 a 18 anos indica que este é o período etário mais afetado pelos homicídios. Os indivíduos nesta idade são os principais impulsores e vítimas das práticas violentas, de acordo com dados das pesquisas nacionais mais recentes, como a da UNICEF acima citada.

A mortalidade de adolescentes no Brasil é bem mais freqüente nas grandes cidades e regiões metropolitanas, áreas que também concentram os mais altos índices de desigualdades sociais e econômicas. Esses jovens são moradores de zonas precarizadas social e economicamente e, também, de zonas carentes e sem acesso às conquistas da modernidade informacional, um fator que, se não determina, pelo menos condiciona e propicia ainda mais o aumento significativo da violência urbana.

1.4 Sobre a Baixa Renda nesta pesquisa

Consideramos, neste artigo, como sendo de baixa renda os jovens provenientes de famílias moradoras de zonas precárias, com renda mensal de até três salários mínimos, cerca de R \$ 900,00 ou US\$1.980.

A grande maioria dos jovens mortos violentamente nas grandes cidades brasileiras é, na sua quase totalidade, proveniente de famílias de baixa renda, moradoras de favelas, que aqui denominamos zonas precárias ou assentamentos autoproduzidos, sem planejamento urbano.

Queremos identificar espacialmente onde se encontram esses jovens e averigüar se a localização dos Telecentros está ou não adequada à sua distribuição espacial, visto que esses jovens de 15 a 18 anos são potencialmente futuras vítimas críticas do panorama da violência em Porto Alegre e deveriam ser os beneficiários mais diretos de uma política de prevenção da violência na cidade. 
Há mais de vinte anos, o DIEESE² estima um valor do salário mínimo bem acima dos estipulados pelos sucessivos Governos, para que seja suficiente para o atendimento das necessidades dos trabalhadores e de suas famílias, conforme prevê o próprio artigo 7 da Constituição Federal do Brasil.

Em uma estimativa realizada há mais de seis anos (fevereiro de 2000), o DIEESE já apontava o valor de R\$930,83, ou seja, cerca de US\$2.046,00 nos dias atuais, como o valor de renda mensal necessário para atender o que determina a própria Constituição Federal do país ${ }^{3}$.

Pensamos que três salários mínimos no Brasil (cerca de US\$300) como renda mensal para uma família conferem, sem nenhuma dúvida, uma situação de baixa renda e muita precariedade econômica e social.

Também de acordo com a Pesquisa Nacional por Amostra de Domicílio (PNAD), realizada em 2004 pelo IBGE, demonstrou-se o perfil da população de baixa renda brasileira em relação à posse dos bens mais difundidos nos domicílios. Assim, dos entrevistados, 72,1\% tinham geladeira; 81,7\% tinham rádio e $82,5 \%$ tinham televisão; no mesmo grupo, nota-se uma diminuição ao acesso dos bens menos comuns, 6,1\% tinham freezer, 7,6\% possuíam máquina de lavar roupa e 1,4\% contavam com microcomputador. Nessa pesquisa a maioria dos estudantes estudava na rede pública de ensino, $84 \%$ do grupo de zero a dezessete anos estudava em escolas públicas.

No entanto, um fator interessante na pesquisa do IBGE acima citada, surge quando os pesquisadores procuraram identificar o que levava os jovens a não freqüentarem a escola: $34 \%$ das pessoas de 0 a 17 anos de idade não iam à escola ou creche por vontade própria ou dos pais ou res-

2 DIEESE significa Departamento Intersindical de Estatística e Estudos Sócio-Econômicos. Trata-se de uma associação civil, pessoa jurídica de direito privado, sem fins lucrativos ou econômicos que congrega e é constituída por entidades sindicais de trabalhadores do Brasil para pesquisa e assessoria sindical, amplamente reconhecida tanto por entidades sindicais de trabalhadores, como por entidades e associações empresariais. Ver: http://www.dieese.org.br.

3 Sobre a problemática do salário mínimo e a posição do DIEESE ver: http://www.dieese.org.br/esp/ salmin/sergio.xml. 
ponsáveis, ou não chegavam à conclusão da série ou do curso desejado. Outro motivo que afastou crianças e adolescentes dos estabelecimentos de ensino foi terem de ajudar nos afazeres domésticos, trabalharem ou procurarem trabalho $(2,7 \%)$ e a falta de dinheiro para as despesas $(2,5 \%)$, como mensalidade, material escolar e transporte. Entre os gaúchos, 2,1\% na faixa de 7 a 14 anos estão fora das escolas, 17,6 \% dos jovens entre 15 e 17 anos encontram-se excluídos dos colégios e da educação escolar.

A partir da indicação dessas informações e números, visando situar o campo em que a pesquisa foi realizada, vamos traçar a seguir um mapeamento e uma análise da concepção original e atual de política pública de inclusão digital dos telecentros pelos principais gestores e executores dessa política na cidade de Porto Alegre.

\section{Da concepção dos agentes públicos sobre a política pública de "inclusão" digital pelo Telecentro, e de seus limites e dilemas}

À guisa de consideração geral e inicial há, em nossa perspectiva, pelo menos três possibilidades de visões distintas de "inclusão social".

1. Uma delas se refere a políticas, práticas e ações desenvolvidas em favor dos setores sociais que, por razões variadas, decorrentes da estrutura sócioeconômica, ou mesmo por problemas de ordem individual, são ou se tornaram, materialmente excluídos do acesso a bens essenciais, passando a viver sob condições de miséria, ou a sofrer variadas formas de discriminação social, em razão de suas diferenças.

Essa visão enfatiza o entendimento das questões sociais no âmbito compensatório, a partir da crença de que basta suprir as carências imediatas dos excluídos e estará garantida a sua inclusão. 
2. Outra possibilidade de olhar a inclusão social enfatiza o processo de emancipação social e política dos indivíduos e coletivos humanos. Nessa perspectiva, o conceito de emancipação ocupa um papel central. Emancipação é um conceito que não se limita à oferta de condições formais para o exercício da cidadania; ela requer a materialidade de políticas sociais e envolve um processo de crítica à substancialidade do processo social de criação e autocriação dos sujeitos individuais de direitos.

Sob esse ponto de vista, políticas de inclusão são políticas essencialmente voltadas à produção de uma cultura emancipatória; em outras palavras, voltadas à construção de valores nascidos das possibilidades de transformação da consciência individual e coletiva. Isso coloca como problema a questão de como promover a realização da interação ideal em sociedades que são altamente desiguais e excludentes.

3. A terceira possibilidade entende a realidade como um sistema complexo cujos "excluídos" estão também incluídos em uma auto-organização própria que não necessariamente seja governada por um sistema determinístico e dominante e nem cujos procedimentos de inclusão sejam totalmente condicionados por uma ordem exógena. São processos que se inter-relacionam na dialógica ordem-desordem-organização, e a soma de suas partes origina múltiplas possibilidades organizativas de diferentes sistemas existentes em simultaneidade na realidade.

As práticas de inclusão e exclusão social são sempre, nesse sentido, processos históricos entre sujeitos de diferentes governabilidades da sua própria produção e transformação da natureza e da cultura. As práticas inclusivas operam como atratores da tensão entre organizacão e desorganização de diferentes sistemas que permitem a realização de novos estados auto-organizativos ou de reforços de novas rupturas ou de anomias, na interação entre diferentes sistemas sociais.

As concertações das interações sociais são múltiplas negociações, redes de associações de interesses, de co- 
operações e conflitos contextuais, mas tendo as práticas inclusivas e excludentes como fenômenos intersubjetivos relevantes em um contexto interativo. A sociologia permite identificar pela praxiologia social variáveis e variantes de "habitus" 4 e diferenciados recursos disponíveis (econômicos, locativos, autorizativos) presentes na própria dinâmica pré-interativa e pósinterativa dos sujeitos em interação e que são fundamentais para a produção e reprodução de interpretações, compreensões, interesses e ações do fenômeno da exclusão e inclusão social.

No entanto, as políticas públicas envolvidas em socializar ou facilitar o acesso às redes digitais conectadas na internet para a população de baixa renda, demonstram estar inventando uma nova abordagem de inclusão social que denominamos de inclusão tecnológica. Em particular, a prefeitura de Porto Alegre e seus agentes públicos resolveram então adotar essa abordagem.

Para demonstrar essa concepção implícita de inclusão social, que visa incluir publicamente jovens de baixa renda em tecnologias informacionais, vejamos algumas citações de entrevistas de importantes agentes públicos que expressam historicamente o discurso oficial, desde a instalação da Política Pública Municipal dos Telecentros em Porto Alegre, até recentes motivações continuadoras dessa política envolvida em diferentes governos municipais:

A proposta de criação dos Telecentros comunitários aliase a outras iniciativas adotadas pela Prefeitura Municipal de Porto Alegre para reduzir a exclusão digital e promover a cidadania eletrônica, disponibilizando equipamen-

\footnotetext{
4 A idéia de habitus na Sociologia é forte, vem da religião, de vestimentas, de tradições. Apesar da força tradicional do habitus e de seu vínculo a disposições estruturais pré-interativas como os componentes de pertencimento a uma estrutura (classe, posição na estrutura e poder, lutas entre afirmação societal de gêneros...), sua própria reprodução é dinâmica, quase nunca é igual a si mesma ou às condições pré-interativas (BOURDIEU, 1989).
} 
tos de informática e conexão Internet a espaços comunitários da periferia da cidade, onde o acesso a esses recursos é social e economicamente dificultoso para a maioria de seus habitantes (Coordenador inicial do projeto. Entrevista realizada em 2004). (grifos nossos)

...Então, quando se discute inclusão digital, nós trabalhamos mais estes problemas de estruturas de tecnologias que privam e dificultam o alcance da política pública, também, para as regiões periféricas... (Alto escalão do Executivo da Procempa - Empresa Pública Municipal de Processamento de Dados. Entrevista 2005)

...O Estado precisa democratizar o acesso aos equipamentos e à Internet, assim como promover a formação dos cidadãos para o uso das ferramentas (Coordenador da Política Pública dos Telecentros, Porto Alegre, 2006)

Conforme fica implícito na narrativa acima feita por diferentes agentes responsáveis pela instalação e implementação da política pública dos telecentros, verificamos a existência de uma concepção de políticas de inclusão digital motivada principalmente pela simples transferência de equipamentos da modernidade informacional para as áreas tomadas com déficits tecnológicos onde vivem moradores de baixa renda (chamada aqui de zonas precárias), ou seja, trata-se de "levar" a modernidade informacional para as comunidades excluídas das novas tecnologias provenientes dessa nova modernidade informacional. Conforme já informamos, chamamos essa abordagem de inclusão tecnológica.

Queremos demonstrar dois equívocos desta concepção simplificada e reducionista de inclusão social. Um é o problema que chamaremos de aporia espacial e outro o problema da necessidade de considerar o duplo dilema da exclusão: exclusão social e precarização informacional.

Vamos considerar primeiramente o problema da aporia espacial. Mesmo com o declínio - desde os anos 80 - do fenômeno de êxodo rural em 
Porto Alegre, devido ao qual se formaram núcleos habitacionais autoproduzidos em modelagens precárias, e mesmo com a atual experiência de intensa e crescente mudança de espacialização interna da população moradora de baixa renda da cidade, mesmo assim, a capital gaúcha se mantém dentro do perfil majoritariamente periférico herdado das décadas de 60 e 70. Ou seja, a maior parte dos assentamentos autoproduzidos, com elevada precariedade habitacional, ainda se situa na periferia da cidade, longe dos centros "urbanos" mais consolidados. Mais de 70\% da população jovem de baixa renda mora em núcleos de assentamentos autoproduzidos, extremamente carentes de serviços urbanos e nos quais a infra-estrutura informacional está longe de se constituir em realidade. Muitos desses locais não possibilitam sequer uma conectividade precária diante das carências de infra-estrutura informacional presentes nesses locais. Quando falamos em inclusão social de âmbito informacional, certamente estamos também, e principalmente, referindo-nos à Internet e à necessidade de elevada e qualificada conectividade, permitindo também, além de acesso ao texto, o acesso a imagens, músicas, audiovisuais, etc.

Analisando a planta positiva de fibra ótica de Porto Alegre verificamos que a conectividade qualificada da estrada da informação está longe desses núcleos habitacionais. Seria muito primário reduzirmos a idéia de inclusão apenas ao acesso de pontos de infra-estrutura de conexões muito precárias, como se isso permitisse uma efetiva política de inclusão sócio-tecnológica.

Indagado sobre essa abordagem, um importante representante do primeiro escalão (secretário municipal - 2007) do atual governo da Prefeitura de Porto Alegre indicou uma posição crítica a essa perspectiva de política de inclusão digital pelos telecentros, declarando:

A gente tem vinte e oito (28) Telecentros, que é o lugar ideal para capacitar os excluídos digitais e toda a população, gratuitamente... Mas eu quero colocar isso porque a gente fala de inclusão digital e faz pouca inclusão digi- 
tal... nós estamos na idade da pedra da inclusão digital. Mas isso não é uma crítica a quem quer que seja, isso é uma constatação de que a gente ainda fica muito na conversa. Porque lá onde tá o pobre não chegou a tecnologia digital... Então, eu pergunto onde está a inclusão digital. (entrevista com o secretário municipal, 2007)

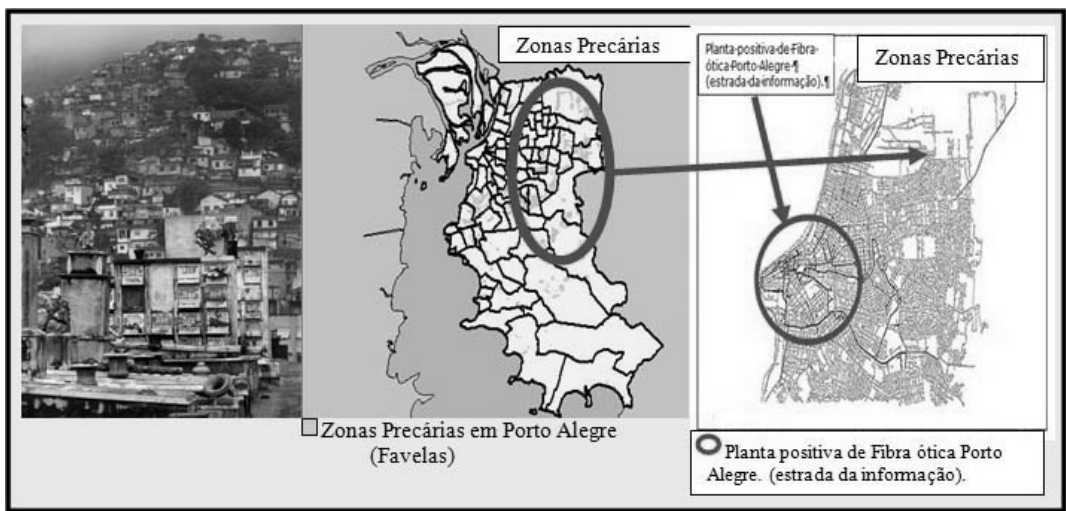

Figura 1. Zonas Precárias x Planta positiva de fibra ótica em Porto Alegre

Essa afirmação, ainda que não se constitua em uma ruptura com a inclusão tecnológica, enfoca de um modo mais detido a profundidade do déficit de acesso ao fluxo de informações, de serviços e de riqueza simbólica produzido pela modernidade informacional.

Nossa primeira crítica à abordagem da inclusão tecnológica se dirigirá em dois sentidos. O primeiro se refere ao problema da aporia espacial e o segundo à necessidade de considerar em países periféricos ou "emergentes" a questão do duplo dilema da exclusão.

Quanto ao primeiro sentido, o da aporia espacial, queremos indicar que, por mais que o discurso oficial tente demonstrar que a modernidade tecnológica está sendo levada para a periferia das cidades e aos jovens 
habitantes dos núcleos precarizados da população de baixa renda, os dados da planta positiva da infra-estrutura informacional demonstraram o contrário, ou seja, a infra-estrutura informacional passa longe de onde vivem esses jovens e suas comunidades. Assim, mesmo levando equipamentos mais ou menos qualificados, mais ou menos potentes de computação pessoal para esses locais, a conexão com a internet será, no mínimo, muito precária ou muito limitada para os fins emancipatórios pretendidos. Sem uma efetiva integração de esforços de políticas públicas ampliadas, mesmo em infra-estrutura informacional básica, ainda que se levem fibras ópticas para esses locais, eles terão certamente uma durabilidade muito curta: ou serão furtados, ou depredados ou a própria infovia ótica se transformará rapidamente em comida de ratos. Seria uma ironia a alta modernidade informacional das fibras óticas converter-se em comida luxuosa de ratos nas nossas periferias tupiniquins não saneadas.

Verificamos também que as escolas mais próximas dessas comunidades, que poderiam ser um local altamente potencializado para a implementação desses centros de atividade de inclusão digital, não são consideradas para fins de instalações dos telecentros, não permitindo, deste modo, integrar outras políticas de integração entre atratores de inclusão digital de curto prazo com uma política de inclusão escolar de longo prazo.

A exclusão das estruturas de informação e comunicação não ocorre para os excluídos e precarizados da modernidade reflexiva apenas em relação ao emprego, suas residências também são afetadas. Os mapas dos novos geoprocessamentos expõem graficamente os déficits de localizações das máquinas sensórias, de receptores e emissores de sinais qualificados de satélites, de cabos de fibra óptica e das redes internacionais sofisticadas de computador nas zonas precárias. Ao mesmo tempo, as infra-estruturas de redes informacionais de alta velocidade são adensadas em poucas zonas das cidades.

Assim, é característico dos agentes mais reflexivos terem acesso a equipamentos digitais avançados de conteúdo informacional, como câmeras digitais de vídeo portáteis, controladores de programação de entretenimento 
digital, enquanto que outros - com menos acesso a esse tipo de produtos tendem a concentrar seu uso nos produtos das linhas operacionais de interações que não compartilham processos reflexivos, como: televisores analógicos, refrigeradores, fogão, aspirador de pó, lavadora e secadora, em que há uma proporção mais elevada de componentes mecânicos em relação aos eletrônicos (LIMA, 2005, p. 365).

Isso vale também para os filhos dos vitoriosos da sociedade do conhecimento reflexivo, que possuem acessos privilegiados a computadores domésticos conectados na Web, a jogos eletrônicos com aceleradores de imagem, simuladores em três dimensões, a teclados e guitarras eletrônicas. Enquanto isso, muitos filhos precarizados na sociedade do conhecimento reflexivo assistem por suas mídias a espetáculos de possibilidades simbólicas e de consumo significativo e aglutinam-se em gangues, interagindo com outras vozes, na maioria das vezes, através de ações violentas e irracionais (LASCH, 1997, p. 162).

É pela também nítida precarização que muitos, por serem mais fracos de recursos informacionais nessa sociedade reflexiva do conhecimento, tornam-se mais violentos. As tensões, inclusive, de relações econômicas criminosas geram novos e particulares guetos de perdedores desintegrados do novo tecido interno dessa nova sociedade.

O segundo sentido de nossa crítica trata ainda de uma questão muito grave desta política de inclusão tecnológica, a saber, a desconsideração do duplo dilema da exclusão das benesses da alta modernidade em países periféricos ou emergentes: a exclusão social da baixa modernidade ainda existente e a exclusão ou precarização informacional da alta modernidade na nossa formação social.

Mesmo sendo as mais recentes teorias sociais da modernidade reflexiva favoráveis à problemática da inclusão reflexiva informacional da alta modernidade, não podemos desconsiderar o problema da herança das desigualdades sociais herdadas pela nossa primeira modernidade. Nesse sen- 
tido, uma política pública de inclusão digital poderia estar desperdiçando esforços e raros recursos em processos "inclusivos" limitados, redutores e até mesmo incoerentes.

Alguns sociólogos que defendem essa abordagem, como, por exemplo, Ulrich Beck (BECK, 1992) e Anthony Giddens (GIDDENS, 1991) afirmam que as sociedades contemporâneas se complexificaram tanto, que estamos mudando de uma modernidade industrial simples para uma alta modernidade mais complexa, movida agora pela reflexividade do conhecimento, ou ainda, para outros, mudamos para sociedades em redes informacionais (CASTELLS, 1999a).

Ulrich Beck afirma que é inegável que o ano de 1989 ficou na História, quando, de forma inesperada, vivenciamos o colapso dos Estados-Nações, considerando-se que o regime comunista soçobrou de um dia para outro no centro e no leste europeu. No entanto, a aparente estabilidade e postura auto-indulgente dos primeiros anos posteriores ao colapso dos ocidentais "vitoriosos", foram, pouco a pouco, sendo afetadas, indicando uma sensação de que o aparente sucesso significava também a derrocada das suas modernas sociedades industriais (BECK, 199, p. 11).

Aqui se coloca uma pergunta relevante para além do déficit tecnológico. Quais os desafios políticos que estão ligados aos desafios da modernidade reflexiva e quais respostas a eles são, em princípio, concebíveis com a exclusão herdada da modernidade simples (industrial)?

Concordamos que a questão da acessibilidade informacional é crucial para a inclusão social na reflexividade contemporânea do conhecimento. As oportunidades de inclusão social dependerão, cada vez mais, da qualidade do lugar e do modo da conexão que os agentes sociais ocupam nessas novas estruturações de interação e de produção de informação e comunicação. Na modernidade reflexiva, o processo de acumulação se transfere para a própria reflexividade informacional. Na nova modernidade do conhecimento reflexivo, as oportunidades de vida são questões de acesso 
não ao capital produtivo ou às estruturas da produção material, mas de acesso à informação complexa e de nódulos que compõem um centro de atividade, gerador de informações diferentes que fazem a diferença, a um mundo simbólico de conhecimento complexo (LIMA, 2005, p. 361).

Assim, as classes sociais de baixa reflexividade podem movimentar-se restritamente apenas no limite máximo da manipulação da informação distribuída, mas, certamente, no âmbito das comunicações simbólicas (imagens e símbolos) não passam de audiência em frente de receptores de estruturas de informação pré-definidas. Os excluídos e precarizados da alta reflexividade informacional na sociedade atual estão integrados apenas por estruturas de informação e comunicação de baixa interatividade, principalmente pela televisão aberta - incluindo em alguns casos a de via satélite e de cabo óptico -, o rádio, os aparelhos de vídeo, etc. Eles possuem acesso a essas mídias que não permitem uma interação ativa do exercício da reflexividade. Aqui, esses jovens de classes da baixa reflexividade são apenas espectadores e manipuladores de programações predeterminadas, até mesmo frente aos horários de exibição e à impossibilidade de alterar reflexivamente (cognitiva e esteticamente) os conteúdos informacionais.

Esta disparidade - entre a aquisição das habilidades de processamento interativo dos símbolos e o acesso ao fluxo dos símbolos nas estruturas informacionais e, também, o acesso ao envio dos símbolos e à sua recepção - tem sido e continuará sendo, cada vez mais, uma mistura poderosa para a crítica política e cultural heterodoxa que exclui um mar de agentes precarizados de reflexividades, muitos já herdeiros da exclusão econômica tradicional de acesso aos benefícios da modernidade industrializada, como negros, mulheres, minorias étnicas e agora, os muitos habitantes cada vez mais crescentes do mapa das "zonas selvagens" (LIMA, 2005, p. 366).

Hoje, quanto mais o trabalho se torna reflexivo, mais ele se apresenta como um projeto intensivo de informação e conhecimento, que agrega valor no mundo do trabalho e, quanto maior a sua densidade e complexida- 
de reflexiva, maior é a agregação de valor e maior é o seu impacto de inovação intensiva para tarefas de implantação de processos de inclusão escolar de ciclo longo.

Diferentemente da sociedade industrial, a posição mais alta no pódio dos ganhadores e o porão dos perdedores e precarizados na modernidade reflexiva não se realiza agora apenas pelo lugar que os agentes sociais ocupam no processo material da produção da sociedade, mas dependerá cada vez mais do lugar que esses mesmos agentes ocupam no "modo de acessar e de produzir informação e conhecimento".

No entanto, os precarizados da reflexividade informacional não são absolutamente excluídos das estruturas reflexivas de informação e comunicação. Isso se dá, em primeiro lugar, por causa do acesso comparativamente aberto ao sistema educacional. É inegável o aumento — na sociedade contemporânea — da acessibilidade escolar, mesmo das classes de baixa reflexividade e das zonas "selvagens" dos guetos. Eles, porém, sabem, e muito bem, que estão ingressando, em uma escala sem precedentes, tanto em escolas profissionalizantes, quanto em universidades massificadas por técnicas disciplinares e de rotinas de emprego, e que, ao mesmo tempo em que são preparados para o mundo do trabalho, esse mundo paulatinamente desaparece.

Da mesma forma, toda uma geração de jovens está sendo "educada" para "aprender a trabalhar" para um mundo de trabalho industrial, racional e cognitivo que cada vez menos existirá, visto que tal trabalho será cada vez mais desempenhado por processos autômatos ou robôs. Esses jovens serão trabalhadores educados para a sociedade industrial quando, em um futuro pouco distante, quase não existirá trabalho vivo no mundo industrial do trabalho. O pior de tudo é que nem sequer teremos mais uma sociedade centrada no processo de produção industrial.

Evidentemente isso não se aplica apenas aos jovens provenientes das zonas precárias das grandes cidades, mas também aos guetos mais específicos de conjuntos habitacionais da velha classe média industrial, na qual os 
pais trabalhadores criaram seus filhos, na esperança de estes ascenderem a uma classe média que cada vez menos existe. Assim, verifica-se que jovens e adultos que já possuíam renda e emprego se somam também, agora como desempregados, a um oceano imenso de despossuídos de renda formal, proveniente dos novos processos oriundos do impacto da ciência e da tecnologia competitiva no mundo do trabalho e que são, assim, incapazes de encontrar renda para atividades qualificadas e complexas do novo mundo do trabalho reflexivo.

A atual educação que modula a disciplina sobre a matéria, sobre o exercício disciplinar da cognição repetitiva, da memória de longo prazo e da racionalização sólida, está restrita a um formar para o mundo do trabalho, para um aprender a trabalhar condicionado a aquisições de um tipo específico de hábitos disciplinadores dos corpos e das mentes de baixa reflexividade para a indústria e a burocracia privada e do Estado, as quais, em grande parte, progressivamente substituirão suas atuais rotinas, executadas por atividade humana, por processos computacionais automáticos e programáveis. Sem ter chance em meio aos empregos da classe trabalhadora, a alternativa passa a ser a formação de gangues, a ocupação das quadras (de futebol), das ruas nas velhas cidades industriais, que deixam de ser públicas e se transformam em um lugar de passagem para nódulos privados, uma rua que "acolhe" muitos meninos e meninas da nova geração de excluídos e precarizados, que os absorve, ao mesmo tempo em que lhes impõe regras de sobrevivência, com seus ditames, tanto de solidariedade, como de violência também racial, tribal, etc.

Assim, cabe-nos perguntarmos: será que as políticas públicas compensatórias dos déficits de precarização informacional pelos Telecentros resolvem plenamente tal problema com a simples transferência de aparatos tecnológicos da modernidade reflexiva para zonas precárias? Também os Telecentros resolvem, por si só e de modo adequado, o problema da acessibilidade informacional?

Como vincular o problema dos déficits de reflexividade dessas comunidades, desses jovens, com a herança da exclusão herdada da baixa reflexividade industrial? Como estes jovens podem enfrentar o problema 
da sobrevivência e quais as alternativas de renda que podem integrar as políticas de compensação da precarização informacional, ou seja, como integrar compensação ou ciclo curto de compensação da modernidade reflexiva com acesso a renda e formação escolar (cultural, artística e científica) qualificada de ciclo longo?

É certo que as comunidades "periféricas" e precarizadas das malhas informacionais interativas, em sua grande maioria, são, até o momento, também excluídas de muitos benefícios realizados ainda pelas conquistas industriais mais elementares (moradia digna, direito gratuito à saúde, educação e escolas qualificadas, presença efetiva da segurança pública, e, principalmente, renda mensal, formal e regular).

Para a grande maioria dessas coletividades, trata-se então de uma dupla situação: 1) Uma exclusão dos benefícios da cidadania industrial básica (moradia, educação, segurança, transporte, renda...) e 2) Comunidades também precarizadas e/ou sem acesso às conquistas informacionais provenientes das mais recentes revoluções nas comunicações e na informação.

Nesse sentido, defendemos que a centralidade da inclusão digital deve integrar-se às escolas com um centro ampliado de inclusão social e desprecarização informacional, aumentando suas atividades, de modo que sejam realizadas em turnos integrais e finais de semana, efetivamente integrando, assim, a inclusão digital com a escolaridade formal, com a inclusão cultural e artística e também com uma política de renda.

Queremos chamar a atenção para a profundidade da dupla estruturação dessa desigualdade, ou seja, para como o novo modo de produzir a sociedade na reflexividade se relaciona com o velho problema da exclusão na modernidade simples.

\section{Ampliação da concepção de inclusão tecnológica}

Entre o final de 2006 e o início de 2007 verificamos, a partir de novos diálogos e entrevistas qualitativas junto aos gestores atuais das políticas dos 
telecentros da Prefeitura de Porto Alegre, duas mudanças significativas e muito positivas no que se refere à inclusão tecnológica: 1) Uma alteração e ampliação no conceito de inclusão social induzida pela política pública dos telecentros; 2) Uma integração da preocupação na execução da política pública dos telecentros com a prevenção da violência para jovens de baixa renda.

Realizando entrevistas mais recentes junto aos gestores públicos municipais, detectamos essa alteração. Trata-se de uma mudança também de concepção e que se deu no interior da coordenação da política pública dos Telecentros, uma vez que a sua coordenação geral deslocou-se, de modo cada vez mais direto, para a atual Secretaria Municipal de Segurança Pública e Direitos Humanos. Essa mudança é também uma mudança de ampliação da concepção de inclusão tecnológica, mas não aconteceu sem tensões e conflitos, como bem demonstra um importante gestor público. Vejamos:

Vocês sabem que na gestão passada esta política pública estava dentro da Procempa ("Empresa Pública Municipal de Processamento de Dados") e na própria gestão passada ela começou a migrar para a Secretaria de Direitos Humanos; e eu era contra e ainda sou, por entender a força que a Procempa tem, por tudo que ela produzia e produz, até hoje. Como, por exemplo, uma infovia, que corta toda a cidade, tem o sistema operacional que vai melhorar o acesso aos telecentros... O papel da comunidade é de tornar-se empreendedora do seu Telecentro, buscando, ela também, apoio do setor privado para manter e continuar provendo aquela estrutura. (Entrevista com um ex-integrante da gestão anterior da política pública dos Telecentros, 2007)

Pensamos que a infra-estrutura informacional é um componente fundamental da inclusão digital, no entanto, isso nada impede, sem considerar sua importância e integração para a política pública de inclusão digital, que a coordenação da política pública em questão esteja sob responsabilidade de outros órgãos públicos menos focados na tecnologia informacional. Veri- 
ficamos, ao contrário, que essa mudança geográfica ou funcional dentro do setor público da coordenação foi positiva, pois acabou gerando efetivamente uma ampliação da concepção de inclusão digital tecnológica e enfraquecendo a abordagem da inclusão tecnológica. Por exemplo, ao perguntarmos a um dos atuais coordenadores da gestão da Política Pública dos Telecentros, que se encontra sob a responsabilidade da Secretaria de Direitos Humanos e Segurança Urbana da Prefeitura de Porto Alegre, se houve ou não alteração na concepção herdada do Governo anterior nessa política pública, encontramos diferentes afirmações que apontam neste sentido:

Sim, nós alteramos no sentido de que fechamos uma parceria recentemente com o SEBRAE ${ }^{5}$ para que os usuários possam ter a possibilidade de usar os cursos à distância empreendedores. São quatro cursos... ...Estamos encaminhando a questão junto ao Centro de Integração Empresa-Escola (CIEE) ${ }^{6}$ para que os telecentros tenham condições de proporcionar aos usuários cursos (profissionais) [...] o CIDADANIA À DISTÂNCIA com o CIEE já está na segunda edição; na primeira 75\% dos jovens de 18 a 24 anos carentes financeiramente que participaram ingressaram no mercado de trabalho, também a questão de estágio, nós pretendemos implementar do ponto de vista pedagógico cursos de preparação para o trabalho nos telecentros. São três horas por dia; para que essas pessoas que participaram deste curso possam ser encaminhadas ao mercado de trabalho através do CIEE, que tem uma gama de relações com a empresa privada...

\footnotetext{
5 SEBRAE. Sigla de uma organização nacional no Brasil, corresponde a Serviço Brasileiro de Apoio às Micro e Pequenas Empresas. É uma organização que trabalha desde 1972 pelo desenvolvimento sustentável das empresas de pequeno porte.

6 Trata-se da sigla do Centro de Integração Empresa-Escola (CIEE), instituição filantrópica com 42 anos de existência, mantida pelo empresariado nacional cuja meta é encontrar, para os estudantes de nível médio, técnico e superior, uma oportunidade de estágio integrado com seus estudos nas escolas.
} 
...Temos vários projetos ligados ao telecentro como a questão do empreendedorismo onde o SEBRAE vai participar. Serviços do telecentro para o cidadão tipo o TUDO FÁCIL?.

...E os telecentros, através de um curso, podem proporcionar as mínimas condições para que este jovem possa ter uma chance de ingressar no mercado de trabalho, que possa montar até um "curriculum vitae". E, muitas vezes, nem um "curriculum vitae" a pessoa sabe fazer... Tem, também, três telecentros que estão fazendo inscrições para o concurso do Trensurb ${ }^{8}$. (Entrevista com o atual dirigente da Secretaria de Direitos Humanos e Segurança Urbana da Prefeitura Municipal de Porto Alegre, responsável pela gestão da Política Pública dos Telecentros, 2007)

Vemos agora nessas manifestações preocupações sociais mais precisas diante da empregabilidade, do acesso à renda e inclusão social ampliada agora para além do mero acesso de equipamentos da alta modernidade pela população de baixa renda. No entanto, é preciso destacar que, em visitas de campo a diversos telecentros, verificamos, por outro lado, uma desconsideração dos aspectos mais tecnológicos da infra-estrutura informacional tão valorizada - ainda que retoricamente - na perspectiva inclusiva anterior.

Realmente, além de a fibra ótica continuar a passar longe das comunidades de baixa renda, muitos dos telecentros populares estão agora ainda mais precarizados. Alguns carecem até mesmo de uma rede elétrica mínima adequada para as instalações, além de estarem equipados com máquinas que não funcionam e com conexões que não se viabilizam, indicando que a mudança da abordagem mais social da política de inclusão, de algum modo está expressando também uma maior despreocupação com os as-

\footnotetext{
7 Programa de serviços informatizados de atendimento público que integra vários órgãos do Estado, agilizando processos para maior rapidez da execução das demandas dos contribuintes.

8 Trata-se da Empresa Estatal ligada ao Governo Federal que é responsável pela operação dos metrôs nas regiões metropolitanas do País.
} 
pectos tecnológicos dos telecentros situados em zonas mais populares, transformando-os em uma espécie de "lan house de pobre" (expressão cunhada por um dos jovens que freqüentam um desses telecentros).

Pensamos e defendemos que é necessário integrar essa abordagem tecnológica à abordagem social de inclusão e, ainda por cima, expandi-las em uma operacionalização que também as integre ao agenciamento escolar de longo prazo pelas escolas públicas. Isso implicaria em integrar, como já informamos, a inclusão da reflexividade informacional a um ciclo longo de inclusão de conhecimento escolar.

No entanto, é interessante a preocupação com o fator renda na nova abordagem, mas pensamos também que isso poderia e deveria vincular-se mais precisamente não com uma perspectiva profissionalizante da empregabilidade, mas com uma perspectiva educacional de acesso a conhecimento e cultura, para isso vinculando renda à freqüência e ao desempenho escolar e integrando os telecentros às escolas e às políticas de extensão de jornada de atividades escolares, culturais e científicas.

Assim, integraríamos o acesso à reflexividade informacional, o acesso à educação e à cultura na escola, vinculado-os à extensão da jornada escolar, ao acesso à renda e bolsas escolares, alimentação, prevenção de doenças e atendimento clínico de saúde, bem como ao acesso a programações culturais e atividades esportivas. Isso seria realmente algo que poderíamos entender como uma nova concepção de investimentos em prevenção da violência de longo prazo diante de toda uma geração de jovens, cujo "destino" poderia ser efetivamente alterado.

Essa concepção já está presente, de modo ainda um pouco fragmentado, nos agentes políticos que defendem a educação integral, sobretudo para as comunidades de baixa renda, visto que os filhos das novas classes médias e altas da modernidade reflexiva já possuem, de algum modo, essa integralidade, com reforços em cursos de Língua, atividades de danças e diversas atividades culturais complementares ao ensino escolar. 
Outro fator positivo da nova abordagem dos novos gestores da Política Pública dos Telecentros é a preocupação cada vez maior, entre políticas públicas de compensação da precarização informacional, em sua relação com a prevenção da violência, sobretudo entre jovens provenientes das zonas precárias. Em entrevista ao coordenador executivo da atual política pública, perguntamos sobre a relação entre Telecentros e a Prevenção da Violência e ele respondeu que:

A relação é total, porque esta questão que tu colocaste
é quem é que tu colocará para gerir a ferramenta. Por-
que o telecentro é uma ferramenta, primeira coisa que
deve ser feita é agregar pessoas que tenham preocupa-
ção e vínculos com a realidade da comunidade do
telecentro. Porque se tu não tiver pessoas da comunida-
de, você pode colocar o telecentro da melhor qualida-
de e ele não irá servir para nada. (Entrevista, 2007)

No entanto, verificamos que as ações efetivas no foco da modelagem da política pública dos Telecentros para prevenção da violência integrada à inclusão digital ainda é uma preocupação muito genérica e diluída em açõespadrões, sem uma densidade estratégica singular.

A pesquisa apontou para caminharmos mais diretamente para a operacionalização da relação entre exclusão, desprecarização informacional e prevenção da violência, sobretudo para jovens moradores de zonas precárias.

\section{Palavras Finais: modernidade simples, modernidade reflexiva, narcotráfico e prevenção da violência}

Verificamos neste artigo que as políticas públicas de inclusão digital, viabilizadas pelos Telecentros em Porto Alegre, foram originalmente motivadas por uma concepção reducionista que chamamos de inclusão e acessibilidade tecnológica. Apontamos que, apesar dos méritos da política com- 
pensatória da precariedade informacional, ou da modernidade reflexiva para as comunidades de baixa renda, a problemática envolve complexidades muito maiores e integração de iniciativas com política de longo ciclo, principalmente no tocante à renda e na escolarização científica, cultural e tecnológica qualificada a ser devidamente oferecida pelas escolas públicas.

O Estado, cada vez mais carente de recursos, depara-se com um duplo dilema no enfrentamento da inclusão da modernidade reflexiva para as camadas de jovens pobres, moradores de assentamentos precários (zonas selvagens) das cidades brasileiras. 1. O problema da exclusão desses jovens da modernidade simples (industrial), sobretudo no que diz respeito a renda e acesso qualificado à escolaridade. 2. O problema da desprecarização do acesso da modernidade reflexiva para esses jovens, já excluídos dos benefícios conquistados pela modernidade simples. Em plena crise de financiamento da esfera pública atual, esses dois dilemas assumem uma dimensão altamente desafiadora.

A problemática da reinvenção da Esfera Pública é, assim, um dos calcanhares mais significativos da expressão da violência nas cidades brasileiras. $\mathrm{O}$ mesmo acontece com políticas públicas de inclusão social dos telecentros. $\mathrm{O}$ velho sistema industrial está desmoronando, não pela luta de forças antagônicas no seu interior, mas - pasmem - como decorrência do seu próprio sucesso. A modernização reflexiva significa, na verdade, a possibilidade de uma (auto) destruição criativa de toda uma era: aquela da sociedade industrial mesmo em países semiperiféricos e/ou "emergentes" como o Brasil.

O "sujeito" dessa destruição criativa não é, deste modo, a revolução, nem as massas proletarizadas, como pensavam Marx e os marxistas, mas, ao contrário, os trabalhadores precarizados de reflexividade, cada vez mais substituídos por programas e máquinas computáveis. Se, no fundo, a modernização simples (industrial de baixa reflexividade) significou primeiro a desincorporação e, segundo, a reincorporação das formas sociais tradicionais pelas formas sociais industriais, então a modernização reflexiva signifi- 
ca, em primeiro lugar, a desincorporação e, em segundo, a reincorporação das formas industriais por outra modernidade (BECK, 1997, p. 12).

No entanto, podemos perguntar-nos: sob quais políticas de compensação dos déficits de modernidade reflexiva podem ser transformadas as determinadas situações sociais herdadas da sociedade industrial de baixa reflexividade? Será que as políticas de compensações de modernidade reflexiva contêm uma chave para seu autocontrole e sua autolimitação? Ou ela simplesmente libera mais um redemoinho em um turbilhão de acontecimentos sobre os quais não se tem mais nenhum controle?

As políticas públicas de inclusão digital, como o caso dos Telecentros de Porto Alegre, são sinais visíveis de que estamos começando, na esfera pública estatal, aos poucos, um visível crescimento de um mal-estar que aponta a necessidade de repensarmos e enfrentarmos demandas públicas para além das tradicionais na sociedade industrial.

Aqui queremos introduzir uma questão que nos parece muito significativa nesse sentido. O resgate e a reinserção do Estado em uma qualidade e eficácia diferenciadas de ações públicas que envolvem demandas da modernidade reflexiva, bem como os novos problemas de legitimação diante do necessário refinanciamento da esfera pública, são algumas das questões cruciais para o enfrentamento da violência no Brasil. Por exemplo, nos locais em que o Estado se ausenta, a economia clandestina, cada vez mais sofisticada em redes mundiais de narcotráfico, se auto-organiza.

Desde os primeiros estudos sobre violência, as pesquisas nos têm oferecido um amplo leque de caracterização do perfil social dos infratores, do funcionamento da justiça dos menores e da marginalização social da infância e adolescência nas grandes cidades.

Já na década de 80 , encontram-se estudos sociais também sobre instituições de internamento e identidade deteriorada da juventude das classes sociais de baixa renda e pesquisas que desenvolvem a categoria crítica de menor infrator. No final da década de 80, já possuímos no País uma 
relativa quantidade e qualidade de estudos sobre o campo da "infância e adolescência no Brasil".

Nos anos 90, emergem pesquisas e também novos estudos sobe o perfil das crianças e adolescentes infratores. As pesquisas ofereceram mais informações e análises específicas sobre assassinatos de crianças e adolescentes, sobre a situação violenta da infância no Brasil. Forneceram ainda etnografias dos "meninos de rua", pesquisas sobre fatores de risco nas adesões ao "mundo do crime" - comparando irmãos e primos não-infratores ou estudando jovens infratores em suas ligações com o tráfico de drogas (ZALUAR, 1999).

Para nós, a relação da violência com o crime organizado e com o tráfico de drogas tem uma significância muito relevante diante das políticas de prevenção e de combate à precarização e exclusão dos jovens de baixa renda nas grandes cidades. É o núcleo mais antigo e polêmico da temática violência, no qual se desenvolveram perspectivas sobre a legalização monitorada da economia criminosa vinculada ao tráfico de drogas para o enfretamento na legalidade da organização social do crime nas cidades e de suas relações com as populações locais, a polícia, etc.

A discussão também gira em torno do caráter mais ou menos organizado do varejo do tráfego nas favelas, quadrilhas ou empresas, de sua relação com outras atividades criminosas como lavagem de dinheiro, grupos de extermínio, ou seja, da ruptura dos padrões da criminalidade convencional a partir da chegada da cocaína no comércio clandestino de drogas, realizado, sobretudo, nas zonas precarizadas das grandes cidades brasileiras.

A maior parte dos estudos sociológicos da violência no Brasil localizaram uma mudança da criminalidade e o aumento da violência nas grandes cidades com a chegada da cocaína nas favelas. Esses estudos identificaram claramente, assim, um aumento generalizado dos roubos e furtos a residências, dos veículos e transeuntes, um grau maior de organização social do crime, um incremento da violência nas ações criminais, um aumento acentuado nas taxas de homicídios, o aparecimento de quadrilhas de as- 
saltantes de bancos e instituições financeiras e o aumento de outros crimes violentos envolvendo homicídios como seqüestros, assaltos, latrocínios e estupros.

Essas mudanças se consolidaram e se expandiriam nos anos 80, com a generalização do tráfico de drogas, especialmente da cocaína, que consolidou e envolveu a economia criminosa das drogas em grandes e sofisticadas redes internacionais do narcotráfico e sua estruturação em moldes econômicos relativamente racionais (ou mesmo empresariais), que alterou o seu poder de atração e de recrutamento da força de trabalho adolescente jovem, ampliando todos os efeitos perversos da violência, em transposições de ações que incorporam também a substituição das armas convencionais por outras, tecnologicamente sofisticadas e com alto poder de destruição (COELHO, 1999, VELHO, 1994, 2000, PAIXÃO, 1991, ZALUAR, 1999, 2004, LEEDS, 1998, ADORNO, 1991, MACHADO DA SILVA et alii, 1998, RAFAEL, 1998, SOARES, 1996 (a) e (b), MOREIRA, 2000, MISSE, 1995, 2000).

A questão não é mais reconhecermos ou não essa mudança do padrão de violência nas grandes cidades brasileiras, mas o modo de interpretála e de enfrentá-la, especificando mais variáveis do que outras, dissolvendo especificidades, absorvendo-as, ou não, em dimensões mais abrangentes da violência ante as enormes desigualdades sociais do Brasil.

Precisamos, no entanto, conectar os temas às temáticas mais abrangentes, vinculadas a processos de transformações crescentes em andamento nas sociedades contemporâneas, e bem como sua integração com as dimensões locais e nacionais específicas de nossa modernização incompleta, agudamente contraditória e socialmente predatória (CASTELLS, 1999b).

São múltiplos conectores que sociólogos e cientistas sociais estão utilizando para dotar de maior complexidade a análise dessas questões: 1. A conexão da violência como uma "crise de reciprocidade" (VELHO, 2000). 2. O problema do esgotamento dos modelos de controle social (ADORNO, 1996c). 3. A Globalização da Violência e os impactos dos fenômenos 
culturais contemporâneos (TAVARES DOS SANTOS, 2003). 4. O problema do retrocesso civilizatório (ZALUAR, 1996) e 5. A emergência de uma "sociabilidade violenta" baseada em um novo tipo de individualismo (VELHO, 2000).

De todo modo, a grande maioria dos estudos, desde a pesquisa pioneira de Alba Zaluar na Cidade de Deus, no Rio de Janeiro (ZALUAR, 1994a, 1994b), tende a confirmar e deslindar um complexo dispositivo de produção da violência nas grandes cidades brasileiras, envolvendo delinqüência convencional, tráfico de drogas, grupos de extermínio, corrupção policial e de agentes penitenciários, arbitrariedade e violência da polícia e práticas de justiçamento em acertos de conta entre traficantes, de traficantes com informantes da polícia ou com delinqüentes convencionais e de policiais com delinqüentes convencionais ou traficantes.

Certamente que uma solução mais geral do problema passa pela discussão social e política a ser realizada na sociedade, visando reinserir o Estado efetivamente no controle do mercado de drogas, legalização, políticas endógenas de controle, fiscalização e monitoramento por dentro do sistema de acumulação econômica e de mercado clandestino da droga nas sociedades contemporâneas e ampliação da compensação de renda integrada ao acesso da escolarização e da educação (bolsas) ao imenso contingente de jovens precarizados ou excluídos de uma efetiva educação de qualidade na complexa sociedade da informação.

Enquanto isso, políticas de compensação da exclusão e precarização informacional para jovens em ciclo curto estão em andamento no País. No entanto, temos que pensar mais estrategicamente sobre o dilema da inclusão digital. Não adianta continuarmos desperdiçando energias em uma alergia superficial, quando a sociedade, de modo cada vez menos oculto, está sendo dominada por um câncer fatal, cuja solução mais precisa seria incluir de modo qualificiado na sociedade um amplo tecido social, um povo que nela falta e que, por faltar, impõe sua presença de modo criativo e, algumas vezes, de modo violento e até mesmo perverso. Não há vácuo social, há 
auto-organização da economia clandestina. A violência é uma expressão visível dessa auto-organização econômica, uma atividade socialmente autoorganizada, com regras sociais, culturais e econômicas de um mercado cada vez mais clandestino e cada vez mais globalmente sofisticado.

No caso de Porto Alegre propomos integrar de modo mais detido as políticas de inclusão digital dos telecentros com políticas de prevenção da violência, sobretudo para a população de alto risco em homicídios, os jovens provenientes de famílias com baixa renda, moradores de zonas precárias e que se encontram em processos de fratura e precarização dos seus laços sociais de inclusão escolar de longo prazo. Diante dos parcos recursos públicos existentes, é vital que possamos localizar esses jovens e oferecer caminhos alternativos aos seus "destinos" trágicos. Este seria, para nós, um dos principais pilares dessa política pública, integrando acesso renda (bolsas) e fortalecendo a inclusão digital integrada com uma política de inclusão escolar de longo prazo.

A ineficácia da ação pública sobre a violência é proporcional à eficácia da auto-organização econômica e social da violência. Um judiciário ineficiente, uma polícia mal paga, um Estado cada vez mais falido, políticas sociais de saúde e educação cada vez menos adequadas aos desafios dos novos tempos, falta de incentivo público e privado à pesquisa científica e tecnológica, são apenas sintomas que só explicitam o fortalecimento e a organização da economia clandestina e, assim, por decorrência, da violência auto-organizada.

\section{Public policies of telecentres and violence prevention}

\section{Abstract}

This article is a systematization of part of a search that took place in the nucleus Violence and Citizenship of the Postgraduate Program of the Federal University of Rio Grande do Sul in the period from 2006 to 2008. We intend, from 
documental data and interviews collected, to provide a conception and analysis of the case of public policy for digital inclusion through telecentres in the capital of Rio Grande do Sul (Porto Alegre). We will discuss in this article the conception of digital inclusion that are present both in the first managers who conceived the Hall of Public Policy Telecenters in Porto Alegre (2004) as in the current managers (2007) that give continuity to the implementation of this public policy. We will proceed to an analysis of these concepts, highlighting its virtues and its limits before the theory of modernity reflexive by us adopted. Our final words are aiming to defend and give a bigger and better integration between the policy for digital inclusion of telecentres and the violence prevention to low-income youth, especially the population at risk, between 15 and 18 years old. We also support the integration of the policy for digital inclusion for this population, to be expanded with a long term policy of income and grants for school inclusion.

Keywords: Digital inclusion. Violence prevention. Analysis of public policies.

\section{Referências}

ADORNO, Sérgio. Violência Urbana, Justiça Criminal e Organização Social do Crime. Revista Crítica de Ciências Sociais, v. 33, p. 145-156, 1991.

. Racismo, Criminalidade Violenta e Justiça Penal: Réus Brancos e Negros em Perspectiva Comparativa. Estudos Históricos, v. 9, n. 18, p. 283-300, 1996a.

. Violência e Racismo: Discriminação no Acesso à Justiça Penal. In: SCHWARCZ, L. et alii (Orgs.). Raça e Diversidade. São Paulo: Edusp/Estação Ciência, 1996b. p. 255-275.

A Gestão Urbana do Medo e da Insegurança: Violência, Crime e Justiça Penas na Sociedade Contemporânea. Tese de Livre Docência. São Paulo: FFLCHUSP, 1996C .

ASSIS, Simone G. de; SOUZA, Edinilsa R. de. Morbidade por Violência em Crianças e Adolescentes no Município do Rio de Janeiro. Jornal de Pediatria, v. 77, n. 6, 1995

AZEVEDO, Maria Amélia; GUERRA, Viviane N. As Políticas Sociais e a Violência Doméstica Contra Crianças e Adolescentes: Um Desafio Recusado em São Paulo?. In: AZEVEDO, Maria Amélia; GUERRA, Viviane N. (Eds.). Infância e Violência Doméstica: Fronteiras do Conhecimento. São Paulo: Cortez, 1993.

BAUMAN, Zygmunt. Modernidade Líquida. Rio de Janeiro: Jorge Zahar, 2001.

BARSTED, L. Linhares. Violência Contra a Mulher e Cidadania: Uma Avaliação das Políticas Públicas. Cadernos do Cepia, n. 1, 1994.

BECK, Ulrich. Risk society: towards a new modernity. Londres: Sage, 1992. 
. et alii. Modernização reflexiva: política, tradição e estática na ordem moderna. São Paulo: UNESP, 1997.

BRANDÃO, Elinae R. Nos Corredores da DEAM: Um Ensaio Etnográfico sobre Mulheres e Violência Conjugal. Dissertação de Mestrado. Rio de Janeiro: Instituto de Medicina Social/UERJ, 1996.

BOURDIEU, Pierre. O poder simbólico. Rio de Janeiro: Bertrand Brasil, 1989.

CARRARA, Sergio et alii. A Violência Contra a Mulher no Rio de Janeiro. Lei e Liberdade - Fórum, n. 2, 1996.

CASTELLS, Manuel. A Sociedade em Rede. A era da informação: economia, sociedade e cultura; v. 1. São Paulo: Paz e Terra, 1999a.

. O Fim do Milênio. A era da informação: economia, sociedade e cultura; v. 3. São Paulo: Paz e Terra, 1999.

COELHO, Magda P. Crime Organizado e Pobreza: Uma nova Associação. In: Polícia Militar, Estado e Sociedade: Os desafios da Modernidade. Belo Horizonte: Fundação João Pinheiro, 1999. p 55-69.

DWYER, Tom. Informatização nas escolas de ensino: uma reflexão sociológica. In: RUBEN, Guilhermo; WAINER, Jacques; DWYER, Tom (Orgs.). Informática, organização e sociedade no Brasil. São Paulo: Cortez, 2003.

GIDDENS, Anthony. As conseqüências da modernidade. São Paulo: Unesp, 1991.

IZUMINO, Wânia P. Justiça e Violência Contra a Mulher: O papel do Sistema na Solução dos conflitos de Gênero. São Paulo: AnnBlume, 1998.

LASCH, Scott et alii. Modernização reflexiva: política, tradição e estática na ordem moderna. São Paulo: UNESP, 1997.

LEEDS, Elizabeth. Cocaína e Poderes Paralelos na Periferia Urbana Brasileira: Ameaça à Democratização em Nível Local. In: ZALUAR, A. e AIVITO, M. (Orgs.). Um Século de Favelas. Rio de Janeiro: Ed. da FGV, 1998.

LIMA, Gilson. Nômades de Pedra: Teoria da Sociedade simbiogênica. Porto Alegre, 2005.

MACHADO DA SILVA, LUIZ A; FIGUEIREDO, Ademir. A Partir de um Ponto do Jogo do Bicho. Anais da 30ª Reunião Anual da SBPC, São Paulo, 1998.

MISSE, Michel. Cinco Teses Equivocadas sobre a Criminalidade Urbana no Brasil: Uma Abordagem Crítica, Acompanhada de Sugestões para uma Agenda de Pesquisas. Série Estudos, n. 91, Rio de Janeiro, IUPERJ, 1995.

O 'Movimento' - A Consolidação das Redes de Varejo de Tráfico de Drogas no Rio de Janeiro. Trabalho apresentado no IV Simpósio Internacional sobre as Toxicomanias, Rio de Janeiro, NEPAD/UERJ, 2000. 
MORAES, Régis. O Que é Violência Urbana? 2. ed. São Paulo: Brasiliense 1987. (Coleção Primeiros Passos, $\mathrm{n}^{\circ}$ 42)

MOREIRA, Marcelo R. Nem Soldados, Nem Inocentes: Jovens e Tráfico de Drogas no Município do Rio de Janeiro. Dissertação de Mestrado em Ciências. Rio de Janeiro: Escola Nacional de Saúde Pública/Fiocruz, 2000a.

PAIXÃO, Antonio, L. Segurança Privada, Direitos Humanos e Democracia. Novos Estudos Cebrap, n. 31, p 130-141, 1991.

RAFAEL, Antônio. Um Abraço para Todos os Amigos. Niterói: Ed. UFF, 1998.

RUSKOWSKI, Bianca de Oliveira; HEYDE, Carla Junger. Exclusão/Inclusão Digital/Social: Um Estudo de Caso com Moradores de Rua em Telecentro. Trabalho de Conclusão de Curso. Porto Alegre: UFRGS, 2005. (Mimeografado)

SOARES, Luiz. Homicídios Dolosos Praticados Contra Crianças e Adolescentes no Estado do Rio de Janeiro, jan-91 a jul-93. In: SOARES, L. E. et alii. Violência e Política no Rio de Janeiro. Rio de Janeiro: Relume-Dumará/ISER, 1996a.

. Uma Radiografia da Violência no Rio de Janeiro.In: BINGEMER, M. C. L.; $\overline{B A R}$ THOLO JÚNIOR, R. dos S. (Orgs.). Violência. Crime e Castigo. São Paulo, Loyola, 1996 b.

TAVARES DOS SANTOS, José Vicente. The Worldization of Violence and Injustice. In: Current Sociology, v. 50, n. 1, jan. 2002.

. A Sociologia para o Século XXI: análise, responsabilidade e imaginação. In: BARREIRA, César (org). A Sociologia no Tempo: memória, imaginação e utopia. São Paulo: Cortez, 2003, p. 195-213.

VELHO, Gilberto. A Dimensão Cultural e Política do Mundo das Drogas. In: ZALUAR, A. (Org.). Drogas e Cidadania. São Paulo: Brasiliense, 1994.

. Individualismo, Anonimato e Violência na Metrópole. Horizontes Antropológicos, n. 13, UFRGS, 2000.

ZALUAR, Alba. Cidadãos não vão ao Paraíso. São Paulo: Escuta, 1994a.

. Condomínio do Diabo. Rio de Janeiro: Revan, 1994 b.

. Da Revolta ao Crime S. A. São Paulo: Editora Moderna, 1996. 1999.

. Drogas e Cidadania: repressão ou redução dos riscos. São Paulo, Brasiliense,

. Integração Perversa: pobreza e tráfico de drogas. Rio de Janeiro: FGV, 2004.

Recebido: 09/07/2007

Aceite final: 18/06/2008 